\title{
Abnormalities of the PRMT1-ADMA-DDAH1 metabolism axis and probucol treatment in diabetic patients and diabetic rats
}

\author{
Xi Mei ${ }^{1}$, Jun Zeng ${ }^{2}$, Dong-Fang Liu ${ }^{3}$, Ye Zhao ${ }^{2}$, Hui-Lan Yang ${ }^{1}$, Yao Li $^{1}$, Ping Qiu ${ }^{1}$, Ming-Wei Tang ${ }^{1}$ \\ ${ }^{1}$ Department of Endocrinology and Metabolism, The First Affiliated Hospital of Chengdu Medical College, Chengdu, China; ${ }^{2}$ School of Bioscience \\ and Technology, Chengdu Medical College, Chengdu, China; ${ }^{3}$ Department of Endocrinology and Metabolism, The Second Affiliated Hospital of \\ Chongqing Medical University, Chongqing, China \\ Contributions: (I) Conception and design: X Mei; (II) Administrative support: Y Zhao; (III) Provision of study materials or patients: X Mei; (IV) \\ Collection and assembly of data: X Mei, DF Liu; (V) Data analysis and interpretation: X Mei; (VI) Manuscript writing: All authors; (VII) Final \\ approval of manuscript: All authors. \\ Correspondence to: Xi Mei. Department of Endocrinology and Metabolism, The First Affiliated Hospital of Chengdu Medical College, 278 Baoguang \\ Road, Chengdu 610500, China. Email: messi0802@163.com; Ye Zhao. School of Bioscience and Technology, Chengdu Medical College, 601 Xindu \\ Avenue, Chengdu 610500, China. Email: zhaoye525@cmc.edu.cn.
}

Background: Symmetrical dimethylarginine (ADMA) endogenously inhibits nitric oxide synthase (NOS) and strongly indicates oxidant stress, whose formation primarily derived from type 1 protein arginine N-methyltransferase (PRMT1) and whose metabolism was governed by type 1 dimethylarginine dimethylaminohydrolase (DDAH1). This study aimed to evaluate participation of the PRMT1-ADMADDAH1 metabolism axis in the kidneys of type 2 diabetes model rats and human subjects, and the effect of probucol on this axis and renal function.

Methods: A total of 30 rats were randomly assigned to a normal group (NC, n=10), diabetic group (DM, $\mathrm{n}=10)$, and a diabetics under probucol treatment group (PM, n=10). Throughout 8 weeks of probucol treatment, plasma NOS, the malondialdehyde (MDA), superoxide dismutase (SOD), nitric oxide (NO), and catalase (CAT) activity were evaluated by chemical colorimetric approach. ADMA concentration was evaluated with an enzyme-linked immunosorbent assay (ELISA) and analysis of expression of PRMT1 and DDAH1 in kidneys with reverse transcription-polymerase chain reaction (RT-PCR), immunohistochemistry (IHC) and western blotting were performed.

Patients with type 2 diabetes were subject to retrospective analysis, and those with a urine albumin/creatinine ratio (ACR) of $>30 \mathrm{mg} / \mathrm{mmol}$ were screened and allocated to the DM group or DM-P group (with probucol therapy); healthy volunteers formed the control group (NDM group). Serum samples were collected for determination of oxidant stress indexes.

Results: The expression of DDAH1 in the kidney, and the plasma NOS, NO, SOD, and CAT activities in diabetic group were lower, while MDA and the expression of PRMT1 and ADMA were higher in contrast to the control group. In diabetics rats receiving probucol, the expressions of DDAH1 and ADMA were downregulated, whereas that of PRMT1 was upregulated. Probucol inhibited the indexes of oxidative stress and improved the kidney function in both diabetic rats and humans.

Conclusions: We found that the expression of the PRMT1-ADMA-DDAH1 axis was altered in the kidneys of diabetic rats. Moreover, results indicated that probucol therapy regulates expression at both ends of this axis, which may preserve renal function by reducing oxidant stress. Therefore, probucol may partially restore expression of the PRMT1-ADMA-DDAH1 axis in diabetic kidneys, immigrate oxidant stress, and enhance renal function.

Keywords: Type 2 diabetes mellitus; kidney; asymmetric dimethylarginine (ADMA); probucol

$\wedge$ ORCID: 0000-0002-6779-5106. 
Submitted Jan 27, 2021. Accepted for publication Mar 25, 2021.

doi: 10.21037/apm-21-417

View this article at: http://dx.doi.org/10.21037/apm-21-417

\section{Introduction}

Complications of diabetes, including variety of macrovascular and microvascular issues, may negatively affect patient outcomes and prognoses. The most frequent microvascular complications in type 2 diabetes patients are diabetic nephropathy, which clinically causes terminal-stage renal disease (1). Prior studies have explicitly elucidated the role of oxidant stress as a key factor in the progression of diabetic complications $(2,3)$; however, the involvement and interaction of specific molecules and pathways in the progression of these complications has remained inexplicit.

It is understood that asymmetrical dimethylarginine (ADMA) is a major endogenously derived methylated arginine which endogenously inhibits nitric oxide synthase (NOS) and participates in endothelial dysfunction (4-6). According to recent studies, ADMA could elevate the level of reactive oxygen species (ROS), thus inducing oxidant stress $(7,8)$. In addition, patients with elevated plasma concentrations of ADMA were carrying cardiovascular risk factors such as hyperlipidemia (9), hypertension (10), diabetes (11), and end-stage renal disease (ESRD) (12). Protein arginine $\mathrm{N}$-methyltransferase (PRMT) and dimethylarginine dimethylaminohydrolase (DDAH) are involved in ADMA regulation. Over $85 \%$ of ADMA is generated by type 1 PRMT (PRMT1) (13); DDAH in rats metabolized over $90 \%$ of the circulating ADMA (14), and type 1 DDAH (DDAH1) was responsible for more than $70 \%$ of ADMA metabolism (15). In sum, these proteins form the PRMT1-ADMA-DDAH1 metabolic axis that is related to oxidant stress and regulates the ADMA concentration in the blood and tissues; therefore, both ends of this axis are vulnerable to redox reactions (16). Furthermore, recent studies have shown impairment in the PRMT1-ADMADDAH1 metabolic axis in the vasculature of diabetic rats $(15,17)$. However, the role of this metabolic axis in the progression of diabetic kidneys has remained inexplicit.

Probucol is a potent antioxidant drug which inhibits lipid peroxidation and oxidatively modifies low-density lipoprotein particles in vitro, circumnavigates endothelial impairment and reduces blood ADMA concentrations in rats (18). Few studies have demonstrated that probucol substantially decreases the ADMA level, concomitantly with a reduction in the PRMT-1 activity and elevation in the DDAH expression in endothelial cells (19). Recent studies have suggested that this has a beneficial impact on renal disease (20). However, few intervention trials have subjected this effect to evaluation of probucol on the PRMT1ADMA-DDAH1 metabolic axis in tissues, particularly in the kidneys, kidney tissues, and reported inexplicit results.

This study aimed to research the expression of this metabolic axis in the kidneys of diabetic rats and the effect of probucol on the axis and its function. Therefore, we also investigated probucol as a supplemental therapy for renal protection, lowering oxidant stress, reducing urinary protein excretion rate, and enhancing renal function in diabetic patients.

We present the following article in accordance with the ARRIVE reporting checklist (available at http://dx.doi. org/10.21037/apm-21-417).

\section{Methods}

\section{Animal preparation}

We made a purchase of 30 male Sprague-Dawley rats, aged 7 weeks, and weighted $160.30 \pm 20.09 \mathrm{~g}$ from the Laboratory Animal Center of Chengdu Medical College. Study protocols were reviewed and approved by the Animal Research Committee of Chengdu Medical College. Experiments were performed in compliance with Chinese national standard 'Laboratory Animals and Environmental Facilities' and the relevant laboratory animal experiment regulations of Chengdu Medical College for the care and use of animals. All rats were housed in a temperaturecontrolled room at $22 \pm 2{ }^{\circ} \mathrm{C}$, humidity at $50 \% \pm 5 \%$, under a $12 \mathrm{~h} \mathrm{light/dark} \mathrm{cycle,} \mathrm{and} \mathrm{food} \mathrm{and} \mathrm{tap} \mathrm{water} \mathrm{were} \mathrm{freely}$ available. Rats were housed in our laboratory environment within 7 days before the experiment. The rats were allocated to a normal control group ( $\mathrm{NC}$ group, $\mathrm{n}=10$ ) and an experimental group $(n=20)$. The $\mathrm{NC}$ rats were fed a standard diet provided by the Laboratory Animal Center of Chengdu Medical College, whereas the experimental rats were given a fat- and sugar-rich diet $(68.5 \%$ standard diet, $15 \%$ lard, $15 \%$ sucrose, $0.5 \%$ bile salt, and $1 \%$ cholesterol). At 4 weeks thereafter, the experimental group rats were 
injected with streptozotocin intraperitoneally (STZ; Sigma; St Louis, MO, USA) diluted in freshly prepared citrate buffer liquid ( $\mathrm{pH} 4.5$ ) at a dose of $30 \mathrm{mg} / \mathrm{kg}$ body weight after an overnight fast. The rats in $\mathrm{NC}$ group were injected with an equal dose of citrate buffer liquid. After 7 days, according to the measurement of the fasting plasma glucose (FPG) levels with tail- nicked blood samples. Rats with the average fasting blood glucose was $>11.1 \mathrm{mmol} / \mathrm{L}$, and the typical symptoms of diabetes were observed including polydipsia, polyphagia, polyuria and weight loss, indicated that the preparation of the diabetes model was successful. FPG levels $>13 \mathrm{mmol} / \mathrm{L}$ were deemed diabetics rats. Diabetics rat modeling was established as elucidated in a prior study (21). The measurement of the glucose was performed with blood glucose test strips (Johnson \& Johnson; Lifescan, CH, UK). Next, the experimental rats were randomly assigned to a diabetics group (DM group, $\mathrm{n}=7$ ) and a diabetic under probucol treatment group (DM-P group, $n=7$ ) and rats were continued with the same enriched diet. Diabetics rats in the PM group were perfused with probucol $(500 \mathrm{mg} / \mathrm{kg} / \mathrm{d})$ into the gastricum for 8 weeks (22), whereas rats in $\mathrm{NC}$ and $\mathrm{DM}$ groups were administered the same dosage of placebo.

All rats were subject to anesthetization with pentobarbital sodium $(35 \mathrm{mg} / \mathrm{kg})$ and euthanasia with cervical decapitation. Next, blood samplings were performed from aorta abdominalis with a heparinized syringe and centrifuged. Plasma was gathered and frozen at $-80{ }^{\circ} \mathrm{C}$. After the rapid removal of kidney and dissection into 3 pieces, we immediately immobilized one of the pieces with a conventional fixation solution and other techniques (23). The remaining 2 pieces were frozen immediately for reverse transcription polymerase chain reaction (RT-PCR) and western blotting, and immunohistochemical (IHC) analysis.

\section{Patients}

\section{Research participants}

Newly diagnosed type 2 diabetes patients aged 50-65 years from the First Affiliated Hospital of the Chengdu Medical College between January 2017 and January 2018 were selected for this study. All procedures performed in this study involving human participants were in accordance with the Declaration of Helsinki (as revised in 2013). The study was approved by Medical Ethics Committee of the First Affiliated Hospital of Chengdu Medical College and informed consent was taken from all the patients. All patients were cleared through oral glucose tolerance test
(OGTT), had complete medical history data and underwent clinical sample collection. The history of the type 2 diabetes patients was analyzed retrospectively; 40 participants with urine albumin/creatinine ratio (ACR) $>30 \mathrm{mg} / \mathrm{mmol}$ were screened and allocated to the DM group or DM-P group. We selected 20 healthy volunteers whose physical health was examined in our hospital during the same period to construct the control group. The DM group included 12 males and 8 females, and the average participant age was $56 \pm 4$ years old. The DM-P group included 10 males and 10 females, and average patient age was $56 \pm 5$ years old. The control group included 10 males and 10 females, and average patient age was $57 \pm 5$ years old. The general characteristics of the groups were comparable $(\mathrm{P}>0.05)$. All diabetic patients were treated with metformin at $850 \mathrm{mg}$ twice a day. The dose of metformin was adjusted according to their blood glucose levels. Random allocation of the participants was made to receive metformin alone (DM group) or metformin and probucol at $500 \mathrm{mg} / \mathrm{d}$ (DM-P group) for a period of 24 weeks.

\section{Serum sample collection and index detection methods} We collected 4-6 mL of peripheral blood from each participant of all groups before the OGTT test; $4-6 \mathrm{~mL}$ of peripheral blood was collected from the control group participants during physical examination. The blood samples were centrifuged to separate the serum; thereafter, determination of superoxide dismutase SOD, catalase CAT, and malondialdehyde (MDA) content with radioimmunoprecipitation kits was performed.

\section{Biochemical indicators of oxidant stress and renal function}

Plasma NOS and nitric oxide (NO) activity were determined by resorting to nitrate reductase methods with available kits (Real-Times (Beijing) Biotechnology Co., Ltd, Beijing, China) from the commercial market. Measurement of FPG concentrations was performed via glucose oxidase method utilizing an automatic analyzer (Beckman Coulter, Brea, CA, USA). Blood urea nitrogen (BUN), creatinine (Cr), and urine ACR levels (Biosino Biotechnology and Science Inc., Beijing, China) were measured using a chemical colorimetric method as per the calculation of absorbance.

\section{RT-PCR analysis}

The kidney tissues were subject to finer grounding with a liquid nitrogen-cooled mortar and pestle and extraction, 
Table 1 The primers of $P R M T 1, D D A H 1$ and $\beta$-actin

\begin{tabular}{ll}
\hline Genes & Primers \\
\hline PRMT1 & Forward: 5'-GAGTTCACCCGATGCCACAAG-3' \\
& Reverse: 5'-TCCGGTAGTCGGTGGAACAAG-3' \\
DDAH1 & Forward: 5'-CTGCCTGACTGCGTGTTCGTG-3' \\
& Reverse: 5'-TCAGCACCTCGTTGATTTGTCC-3' \\
$\beta$-actin & Forward: 5'-GAGAGGGAAATCGTGCGTGAC-3' \\
& Reverse: 5'-CATCTGCTGGAAGGTGGACA-3' \\
\hline
\end{tabular}

total RNAs were extracted according to the manufacturer's directions (Invitrogen, Carlsbad, CA, USA), and its purity and concentration were measured with a nucleic acid protein analyzer (Amersham Biosciences, Piscataway, NJ, USA). We conducted RT-PCR according to previously described methods (24). The primers of PRMT1, DDAH1 and $\beta$-actin are shown in Table 1.

Images were obtained and quantified using Bio-Rad Laboratories Quantity One version 4.6.2 software (Bio-Rad Inc., Hercules, CA, USA).

\section{ADMA measurement}

The concentration of ADMA in kidney tissue was measured with an enzyme-linked immunosorbent assay (ELISA; R\&D Systems; Minneapolis, MN, USA). This assay had a detection limit of $0.05 \mathrm{mmol} / \mathrm{L}$; the relationship between the ADMA concentration and photometric optical densities (ODs) was linear in the range of $0.1-5.0 \mathrm{mmol} / \mathrm{L}$. The ADMA concentration in the kidney tissue was measured in 4 separate experiments, each was run in duplicate; the results are expressions of average \pm standard deviation (SD) values.

\section{Western blotting analysis}

Kidney tissues were subject to dissection into small-sized pieces and homogenization in lysate buffer (Beyotime Institute of Biotechnology; Jiangsu, China) on ice. The concentration of total protein was measured with the bicinchoninic acid (BCA) method (20). Proteins of equal concentration were subject to isolation on electrophoresis and electro-phoretical transfer to polyvinylidene fluoride (PVDF) membranes. The membranes were plugged for $1 \mathrm{~h}$ and subsequently incubated with primary monoclone PRMT1 antibody (1:2,000 dilution; Cell Signaling Technology, Shanghai, China) or DDAH1 antibody $(1: 5,000)$ in Tris-buffered saline containing $4 \%$ evaporated milk at $4{ }^{\circ} \mathrm{C}$ overnight. Rinsing with phosphate buffered saline with Tween-20 (PBST) was performed and the membranes were incubated with horseradish peroxidases (HRP)-conjugated antibodies against mouse $\beta$-actin $(1: 5,000)$ and rabbit $\beta$-actin (1:2,500 dilution; 4A Biotech, Beijing, China) or HRPconjugated anti-rabbit secondary antibody $(1: 1,000)$ for 1 hour. Images were received and quantified within a Bio-Rad VersaDoc imaging system (Amersham Biosciences; UK) with Bio-Rad Quantity One software.

\section{IHC}

The kidney sections were deparaffinized, incubated with $3 \% \mathrm{H}_{2} \mathrm{O}_{2}$, blocking goat serum, and subsequently tinted for detection of PRMT1. The tissue sections were incubated with primary polyclonal antibody against PRMT1 (ZSGBBIO, Beijing, China) and to diluted at 1:1,500 for 2 hours at an ambient temperature. The sections were incubated with a secondary antibody conjugated by HRP and antibody binding was detected using diaminobenzidine (DAB) solution. The average OD was determined with a spectrophotometer and analyzed with Image-Pro Plus 6.0 software (Media Cybernetics Corp., Rockville, MD, USA) for image analysis.

\section{Statistical analyses}

Results were expressed as mean \pm SD values. After a normality and variance testing for homogeneity, normally distributed data was subjected to one-way analysis of variance (ANOVA), after which the Bonferroni's post-hoc test was caried out for comparisons. Statistical analyses were performed using SPSS 23.0 statistical software (IBM, Armonk, NY, USA). A P value $<0.05$ was considered statistically significant.

\section{Results}

\section{The indexes of serum oxidant stress and renal function}

The content of serum oxidant stress indexes SOD, CAT, NOS, and NO in the DM group was substantially lower in contrast to the control group, whereas MDA showed a substantially higher content in contrast to the NC group; $(\mathrm{P}<0.05$; Table 2). Treatment with probucol substantially reinforced the SOD, CAT, NOS, and NO activity in comparison with the levels of $\mathrm{DM}$ rats $(\mathrm{P}<0.01$; Table 2$)$. Blood glucose level in the DM and PM groups were 
Table 2 Comparison of serum oxidant stress indexes among 3 groups of diabetic rats

\begin{tabular}{|c|c|c|c|c|c|}
\hline Groups & $\mathrm{NO}(\mu \mathrm{mol} / \mathrm{L})$ & $\mathrm{NOS}(\mu \mathrm{mol} / \mathrm{L})$ & CAT (U/mL) & $\mathrm{SOD}(\mathrm{U} / \mathrm{mL})$ & $\mathrm{MDA}(\mathrm{U} / \mathrm{mL})$ \\
\hline Diabetic untreated & $28.67 \pm 0.26^{\Delta}$ & $13.12 \pm 0.24^{\Delta}$ & $27.1 \pm 1.6^{\Delta}$ & $157 \pm 5.12^{\Delta}$ & $3.87 \pm 0.63^{\Delta}$ \\
\hline Probucol treatment & $38.14 \pm 0.62^{\star a}$ & $15.56 \pm 0.35^{\Delta a}$ & $31.8 \pm 1.2^{\star a}$ & $179 \pm 2.48^{\star a}$ & $2.96 \pm 0.18^{\star b}$ \\
\hline
\end{tabular}

${ }^{\star} \mathrm{P}<0.05,{ }^{\triangle} \mathrm{P}<0.01$ vs. the normal control group; ${ }^{\mathrm{a}} \mathrm{P}<0.05,{ }^{\mathrm{b}} \mathrm{P}<0.01$ vs. the group of diabetics without treatment. NO, nitric oxide; $\mathrm{NOD}$, nitric oxide synthase; CAT, catalase; SOD, superoxide dismutase; MDA, malondialdehyde.

Table 3 Changes in renal function at different times during 24-week treatment with probucol in diabetic patients

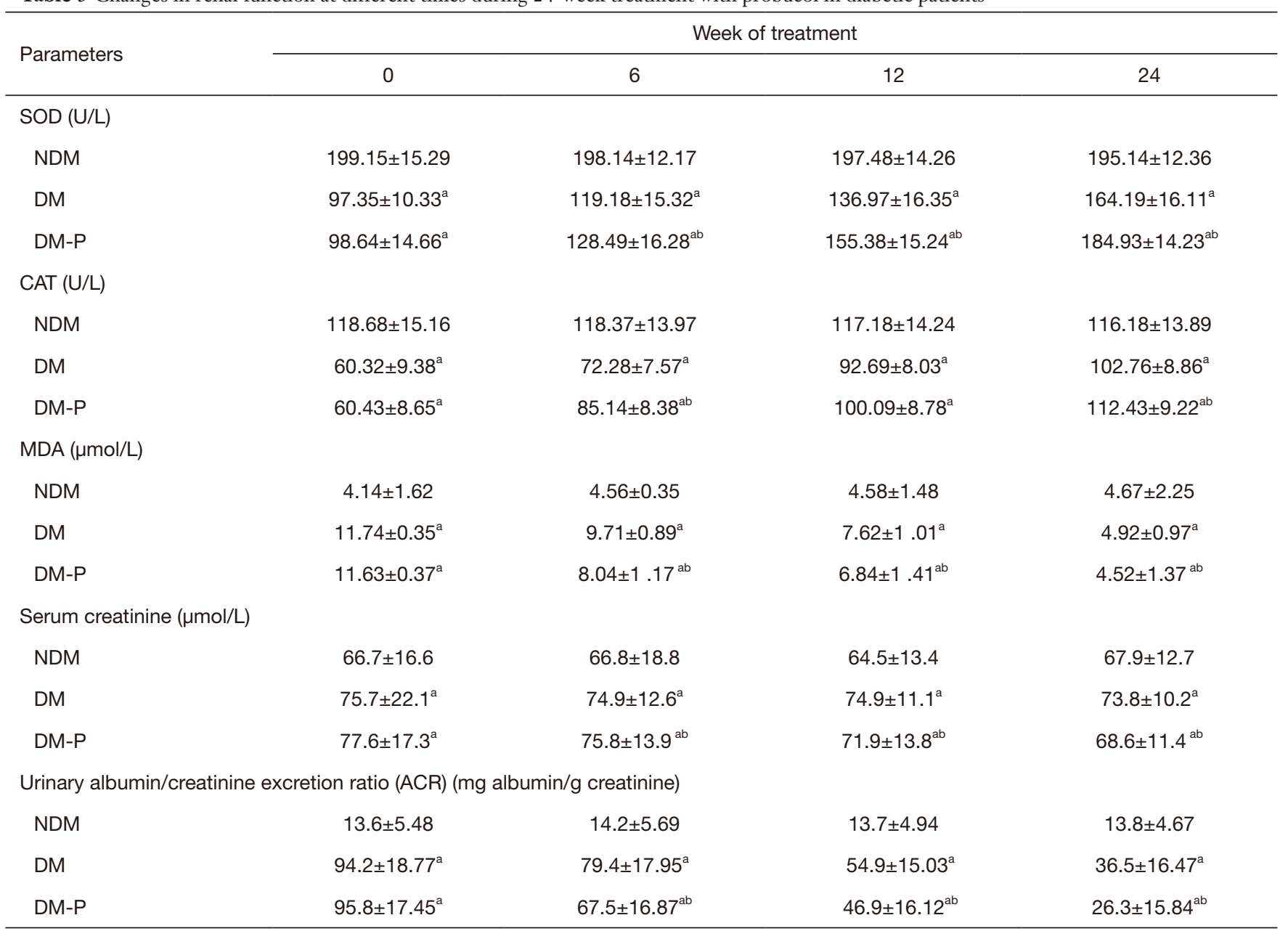

Compared with NDM group, ${ }^{a} \mathrm{P}<0.05$; compared with DM group, ${ }^{\mathrm{b}} \mathrm{P}<0.05$. SOD, superoxide dismutase; CAT, catalase; MDA, malondialdehyde; NDM, non-diabetes mellitus/control; DM, diabetes mellitus; DM-P, diabetes mellitus-probucol.

substantially more elevated than those in the NC group $(\mathrm{P}<0.01 ;$ Table 2). The same results were seen in patients with diabetes, with treatment of probucol, the level of plasma SOD and CAT activity were substantially increased $(\mathrm{P}<0.05$; Table 3), whereas plasma MDA was decreased in contrast to the control group $(\mathrm{P}<0.05 ;$ Table 3). The renal function indexes BUN, Cr, and ACR levels in the PM group were substantially lower than in the DM group $(\mathrm{P}<0.05$; Tables 3,4); however, the levels were higher than those in the NC group $(\mathrm{P}<0.05$; Tables 3,4). 
Table 4 Change in plasma biochemical parameters in diabetic rats

\begin{tabular}{lcccc}
\hline Groups & FPG $(\mathrm{mmol} / \mathrm{L})$ & BUN $(\mathrm{mmol} / \mathrm{L})$ & $\mathrm{Cr}(\mu \mathrm{mol} / \mathrm{L})$ & $\mathrm{ACR}(\mathrm{mg} / \mathrm{mmol})$ \\
\hline Normal control & $5.91 \pm 0.90$ & $7.14 \pm 0.43$ & $103.96 \pm 2.72$ & $11.14 \pm 10.5$ \\
Diabetic untreated & $10.58 \pm 1.80^{\Delta}$ & $11.67 \pm 1.65^{\Delta}$ & $159.50 \pm 21.84^{\Delta}$ & $89.85 \pm 41.37^{\Delta}$ \\
Probucol treated & $9.58 \pm 1.48^{\star a}$ & $8.74 \pm 0.62^{\Delta a}$ & $120.56 \pm 6.3^{\Delta a}$ & $64.79 \pm 21.12^{\Delta a}$ \\
\hline
\end{tabular}

${ }^{*} \mathrm{P}<0.05,{ }^{\Delta} \mathrm{P}<0.01$ vs. the normal control group; ${ }^{\mathrm{a}} \mathrm{P}<0.05$ vs. the group of diabetics without treatment. FPG, fasting plasma glucose; BUN, blood urea nitrogen; $\mathrm{Cr}$, creatinine; $\mathrm{ACR}$, albumin/creatinine ratio.
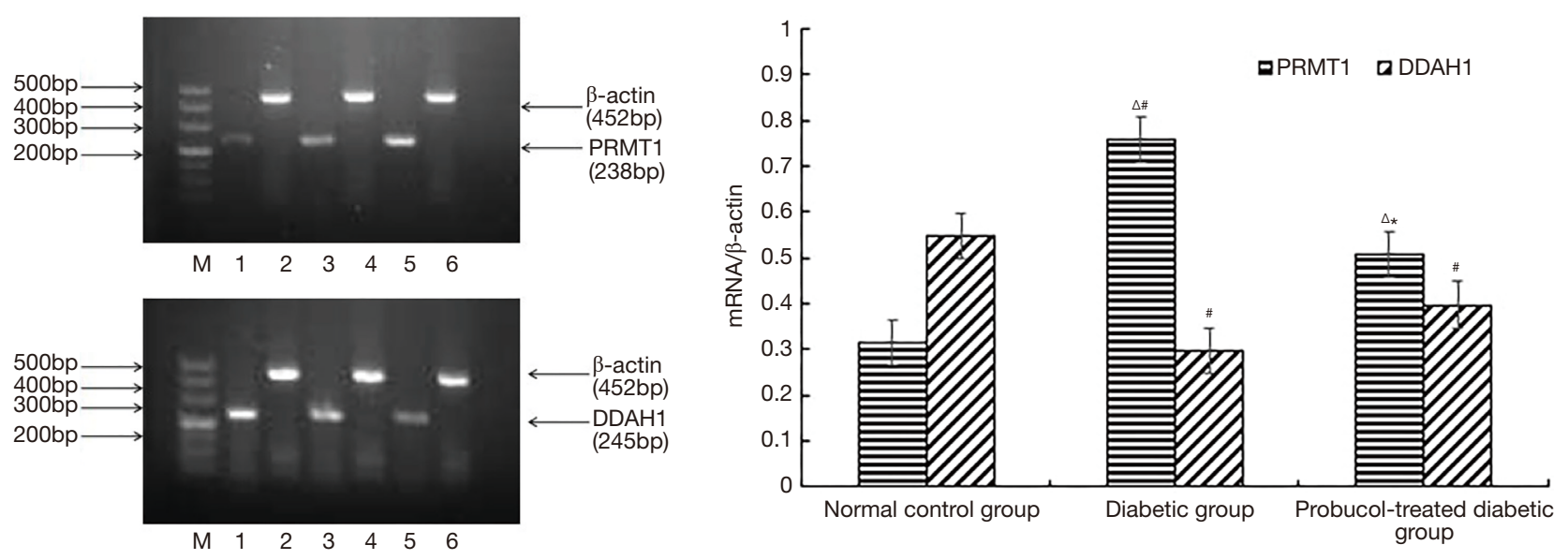

Figure 1 The mRNA expression of PRMT1 and DDAH1 in the kidneys of rats in the normal control group (lane 1), diabetic group (lane 5), and probucol-treated diabetic group (lane 3 ) is determined by the RT-PCR. $\beta$-actin, lane 2 , 4, and 6 . ${ }^{*} \mathrm{P}<0.05$, ${ }^{\#} \mathrm{P}<0.01$ in contrast to the normal control group; ${ }^{\triangle} \mathrm{P}<0.05$ in contrast to the group of diabetics without treatment. RT-PCR, reverse transcription polymerase chain reaction.

\section{ADMA concentration}

The average concentration of ADMA in the DM group was substantially increased in comparison with that in the $\mathrm{NC}$ group $(314.70 \pm 40.85$ vs. $159.99 \pm 32.08 \mu \mathrm{mol} / \mathrm{L} ; \mathrm{P}<0.01)$. Probucol substantially inhibited the increase in the ADMA concentration according to the observations in the DM group $(218.66 \pm 25.38$ vs. $314.70 \pm 40.85 \mu \mathrm{mol} / \mathrm{L} ; \mathrm{P}<0.01)$.

\section{PRMT1 and DDAH1 mRNA expression}

The expression of PRMT1 messenger RNA (mRNA) in the kidney tissues was higher in the DM compared with NC rats $(\mathrm{P}<0.05)$; and there was decreased expression in the $\mathrm{PM}$ group in contrast with the $\mathrm{DM}$ group $(\mathrm{P}<0.01)$. The mRNA of DDAH1 in the kidney tissues had lower expression in the DM group in comparison with the $\mathrm{NC}$ group $(\mathrm{P}<0.05)$; treatment with probucol increased the expression of DDAH1 mRNA more than that in the DM group $(\mathrm{P}<0.05$; Figure 1).

\section{PRMT1 and DDAH1 protein expression}

According to the results of western blotting analysis, PRMT1 in the kidneys had a lower protein expression in the $\mathrm{NC}$ group in comparison with the protein expression in the $\mathrm{DM}$ and $\mathrm{PM}$ groups $(\mathrm{P}<0.01)$; however, $\mathrm{PRMT} 1$ protein expression was higher in the DM group in comparison with the PM group $(\mathrm{P}<0.05)$. Comparatively, DDAH1 protein expression in the kidneys was decreased more in the $\mathrm{DM}$ group than in the $\mathrm{NC}(\mathrm{P}<0.01)$ and $\mathrm{PM}(\mathrm{P}<0.05)$ groups (Figure 2). Treatment with probucol decreased the protein expression of PRMT1 and increased the protein expression of DDAH1 in diabetics rats.

\section{IHC}

The IHC staining for PRMT1 in the DM and PM groups had a higher reactivity in the glomerular and epithelial cells of the proximal tubules than that in the NC group (Figure 3). The average OD of PRMT1 was lower in 
A

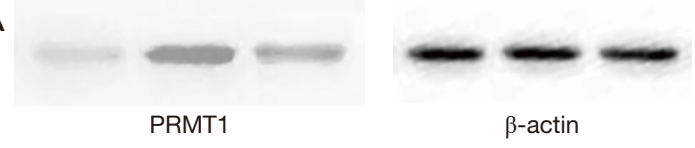

B

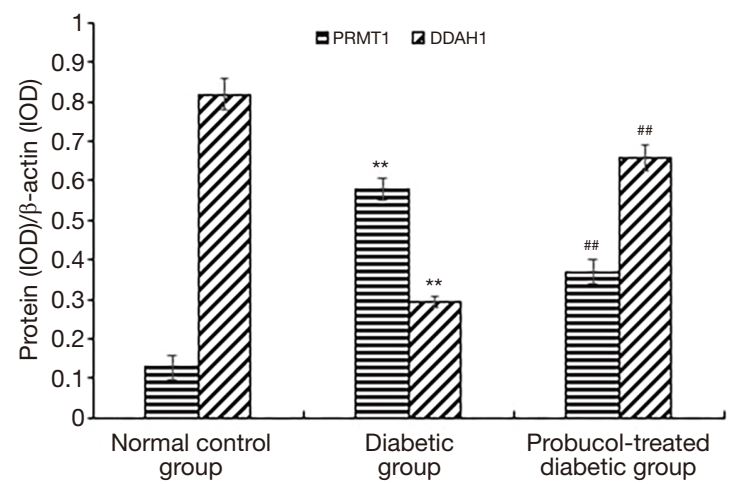

Figure 2 Expression of PRMT1 and DDAH1 proteins. (A) Western blotting analysis showing the presence of proteins of PRMT1 (left) and DDAH1 (right) in the kidney of (I) normal control rats; (II) diabetic rats; (III) diabetic rats receiving treatment with probucol (500 mg/kg/d), compared with $\beta$-actin (below). (B) The results of statistical analysis of the protein amount corresponding to $\beta$-actin. Average standard deviation, $\mathrm{n}=3$. ${ }^{* *} \mathrm{P}<0.01$ vs. group of normal control rats, ${ }^{\# \#} \mathrm{P}<0.01$ vs. group of diabetics without treatment. the NC group compared with that in the DM and PM groups $(\mathrm{P}<0.01)$; however, it was higher in the DM group compared to the $\mathrm{PM}$ group $(\mathrm{P}<0.05)$.

\section{Discussion}

Oxidant stress is defined as a disturbance of equilibrium between ROS production, mainly free radicals are produced and antioxidant defense mechanisms, resulting in tissue injury. Considering the physiological conditions, antioxidant defense mechanisms could defend tissues against ROS-induced damage. However, conditions that either develop more free radicals or dilute the antioxidant defense would incur cellular and tissue damage because of free radical accumulation that greatly surpassed the body's scavenging capacity. Oxidant stress is an important change that takes place in the body under the circumstances of high blood glucose levels; further, it serves as an important pathological linkage for mediation of diabetic microvascular complications (23).

Oxidant stress activation could give rise to mass production of oxygen free radicals which participate in oxidizing reactions, damaging the cells; next, the proteins
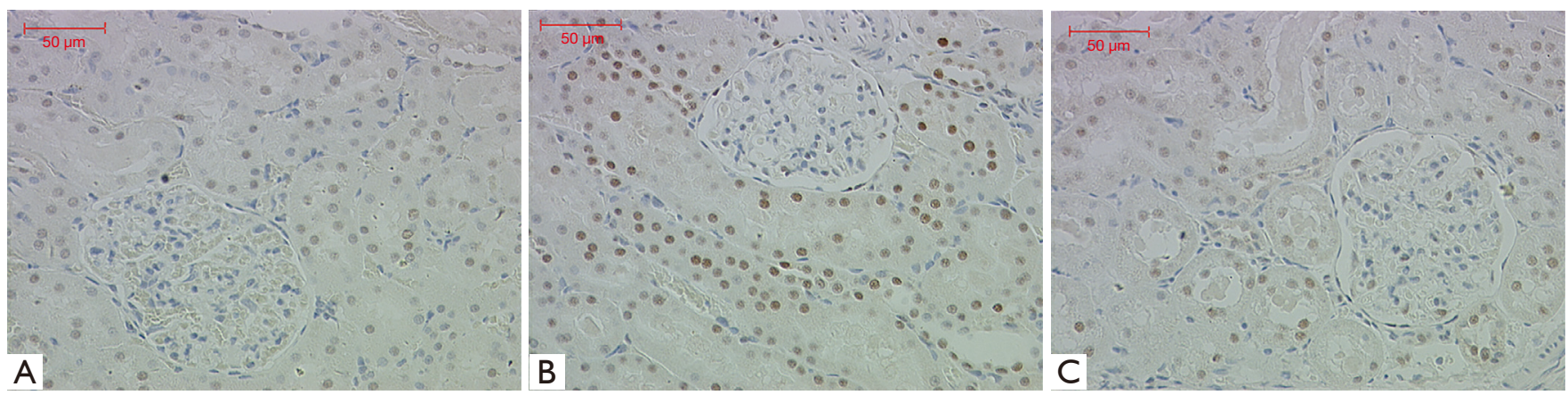

Figure 3 Protective effects of probucol. IHC staining of PRMT1 protein in sections of kidney tissues from the 3 groups of rats. IHC staining (SP, $\times 400)$ of PRMT1 in the kidney tissues of (A) normal control group, (B) diabetic group, and (C) diabetic group under the treatment of probucol. The average optical density (AOD) of PRMT1 in rats. ${ }^{*} \mathrm{P}<0.01$ vs. normal control rats; ${ }^{*} \mathrm{P}<0.05$ vs. diabetic group. A combination of oily and sweet food and injection of streptozotocin into the tectorial membrane ( $30 \mathrm{mg} / \mathrm{kg})$ induced diabetes. Rats in the diabetic group under treatment were perfused with probucol into the gastricum $(500 \mathrm{mg} / \mathrm{kg} / \mathrm{d})$ for 8 weeks. Positive products were colored brownish-yellow. Bar $50 \mu \mathrm{m}$ (streptavidin-peroxides). IHC, immunohistochemical; PRMT1, protein arginine N-methyltransferase-1. (D) Expression of PRMT1 and DDAH1, as determined immunohistochemically, in kidneys of rats from normal control group, diabetic group and probucol group. The average optical density $\left(\mathrm{AOD}, \mu \mathrm{m} / \mathrm{mm}^{2}\right)=\operatorname{sum}($ integral optical density, IOD, $\mu \mathrm{m}) / \mathrm{sum}\left(\mathrm{area}^{2} \mathrm{~mm}{ }^{2}\right)$. The brownish-yellow granules in renal tubules were positive cells. There were a few positive cells in the normal control group (A), a large number of positive cells in the diabetic group (B). There were also a few positive cells in the probucol group (C), which were between the NC group and the DM group. 
leak from the glomeruli, pass into urine, and result in proteinuria (24-26). Prior studies have confirmed that early nephropathy in diabetes was related to high intrarenal $\mathrm{NO}$ and NOS productivity $(27,28)$, whereas mid-term nephropathy and ESRD were accompanied by decreased NO and NOS levels (29).

The kidneys are particularly sensitive to oxidant stress. The production of NO is promoted by ROS, and excessive NO production results in glomerular hyperperfusion and high permeability, leading to renal vasodilatation and reinforced vascular permeability in early stage (30). Meanwhile, there are a variety of antioxidants in the body, and antioxidant enzymes, such as SOD and CAT, can scavenge oxygen free radicals in the body and reduce oxidant stress injury; in the case of excessive activation of oxidant stress, antioxidant enzymes become massively consumed and their levels substantially reduce $(31,32)$. Our analysis of the content of these antioxidant enzymes in our study showed that serum NOS, NO, SOD, and CAT content of the DM group was substantially lower than those in the control group; the higher the ACR was, the lower the serum SOD and CAT content became.

The oxidation reaction of oxygen free radicals and lipid compositions in the endothelial cells and basement membrane cells form MDA (33). In our study, we analyzed the content of these oxidation reaction products and found that the serum MDA content in the DM group was substantially higher than that in the control group; the higher the ACR, the higher the serum MDA. In contrast, the plasma BUN, Cr, and ACR levels were higher in the kidneys of diabetic rats in comparison with those in the kidneys of NC rats. Previous studies have also confirmed that decreased renal function was followed by reinforced oxidant stress in diabetic nephropathy $(34,35)$. However, these studies could not confirm the presence of an imbalance of the PRMT1-ADMA-DDAH1 metabolic axis in reinforced oxidant stress in the kidneys and declined renal function under hyperglycemic conditions.

The chemical ADMA is an endogenous inhibitor of NOS and it has been gradually recognized as a potential risk factor in chronic kidney diseases. Prior studies have declared that oxidant stress may propel the progression of type 2 diabetes mellitus via activation of stress-signaling pathways, resulting in an increased concentration of ADMA and impaired NOS regulation (36,37). Elevated concentrations of ADMA have been observed in type 2 diabetes, hyperlipidemia, hypertension, and other diseases related with oxidant stress in animal models and humans (38).
Therefore, ADMA is considered a risk factor of diabetic nephropathy. It is predominantly generated by PRMT1 and is primarily metabolized by DDAH1, which forms the PRMT1-ADMA-DDAH1 metabolic axis. Both ends of this axis are involved in redox reactions (16). This study showed that the mRNA and protein expression of PRMT1 was elevated and DDAH1 was reduced in the kidneys of diabetic rats compared to those in normal rats. Moreover, the IHC analysis showed increased expression of PRMT1 in the epithelial cells of the proximal tubules of diabetic rats in comparison with those of normal rats. Recent studies have shown the PRMT1-ADMA-DDAH1 metabolic axis in the vascular system of diabetic rats to be impaired $(15,16)$, which is in favor of our conclusions. However, Onozato et al. (39) revealed abnormal expression of PRMT1 and DDAH1 protein in the serum and kidney tissue of type 2 diabetic rats; they also showed that ADMA concentration was related to the expression levels of PRMT1 or DDAH1 protein. Based on these results, we speculated that metabolic abnormality of the PRMT1-ADMA-DDAH1 axis in the kidney is a marker of type 2 diabetes in rats, and this could indicate a novel causative pathway of renal damage that affects the morbidity and progression of diabetic nephropathy.

The ADMA content herein was greater in the kidneys of diabetic rats in comparison with normal control rats. Western blotting analysis and RT-PCR analysis showed that the expression of PRMT1 mRNA and protein were elevated substantially in the kidneys of type 2 diabetic rats, whereas expressions of DDAH1 were reduced. The IHC results also showed that the PRMT1 levels were elevated in the kidneys of diabetic rats. We confirmed that ADMA levels are associated with the expression of PRMT1 and DDAH1, and that changes in the PRMT1-ADMA-DDAH1 axis occur in the kidneys of type 2 diabetic rats. Therefore, any factors that might affect the balance of the PRMT1-ADMADDAH1 axis will cause an ADMA accumulation, increase oxidant stress, increase ROS production, and ultimately lead to a vicious cycle of damage.

Probucol is a widely accepted lipid-lowering drug which is used for treating hypercholesterolemia. It is another potent antilipidemic agent that has an anti-atherosclerotic action and prevents oxidative tissue injury (40). Previous studies have demonstrated that probucol might hinder the progression of early- and advanced-stage diabetic nephropathy and reduce ROS levels by increasing plasma $\mathrm{NO}$ and NOS activity, and reducing the nicotinamide adenine dinucleotide phosphate (NADPH) oxidase activity 
$(41,42)$. Our results confirmed that probucol treatment increased the serum NOS, NO, SOD, and CAT activity. Therefore, we speculated that 8 weeks of probucol treatment could reduce oxidant stress and have a positively protective effect on STZ-induced type 2 diabetes rats' kidneys.

Certain limitations existed herein. For all diabetics, treatment with probucol should be concomitant with metformin treatment for renal protection. Metformin is a well-known classic drug for the treatment of diabetes and has an anti-oxidant effect (43). According to our observations, when the positive effect of probucol on renal function was combined with metformin treatment, the potent antioxidant property increased the avoidance of renal impairment.

We found that probucol had a positive effect on renal function which may be on account of probucol's role in regulating the PRMT1-ADMA-DDAH1 axis. On the basis of these results, we hypothesized that probucol may participate in metabolic regulation at both ends of the PRMT1-ADMA-DDAH1 axis. In fact, our results showed that probucol improves renal function and decreases PRMT1 levels, thereby confirming our hypothesis. Furthermore, we found that probucol had a protective effect on diabetic nephropathy which may reduce ADMA concentration and elevate NOS expression via the inhibition of PRMT1 expression and augmentation of DDAH1 expression. In sum, these changes should help to reduce oxidant stress, promote improved renal function, and delay the morbidity and occurrence of diabetic nephropathy.

Our results strongly supported the hypothesis that the PRMT1-ADMA-DDAH1 metabolic axis could fulfill a necessary role in the diabetes-related degradation of renal function. The protective effect of probucol on renal function in type 2 diabetes rats is related to its involvement in regulation of the PRMT1-ADMA-DDAH1 axis. The protective mechanism of probucol on diabetic kidney is mainly through inhibiting the generation or metabolic pathway of ADMA, regulating the expression of both ends of the metabolic axis of PRMT1-ADMA-DDAH1, inhibiting the expression of PRMT1 and ADMA, and further inhibiting oxidative stress, thus improving vascular endothelial function and protecting renal function. Probucol shows promise as a supplementary therapy to protect the kidneys in type 2 diabetes. The number of rats and human subjects studied in our trial was relatively small, and not all results of animal experiments can be readily extrapolated to humans. Therefore, further experiments are required to evaluate the role of the PRMT1-ADMA-DDAH1 axis in diabetic nephropathy.

\section{Acknowledgments}

Funding: This study was supported by the Key Discipline Construction project of Sichuan Province, Science and Technology Fund project of Chengdu Medical College (CYZ13-027), and Sichuan Collaborative Innovation Center for Elderly Care and Health of Chengdu Medical College (YLZBZ2008).

\section{Footnote}

Reporting Checklist: The authors have completed the ARRIVE reporting checklist. Available at http://dx.doi. org/10.21037/apm-21-417

Data Sharing Statement: Available at http://dx.doi. org/10.21037/apm-21-417

Conflicts of Interest: All authors have completed the ICMJE uniform disclosure form (available at http://dx.doi. org/10.21037/apm-21-417). The authors have no conflicts of interest to declare.

Etbical Statement: The authors are accountable for all aspects of the work in ensuring that questions related to the accuracy or integrity of any part of the work are appropriately investigated and resolved. All procedures performed in this study involving human participants were in accordance with the Declaration of Helsinki (as revised in 2013). The study was approved by Medical Ethics Committee of the First Affiliated Hospital of Chengdu Medical College (NO.: 2019CYFYIRB-BA-01-01) and informed consent was taken from all the patients. Experiments were performed in compliance with Chinese national standard 'Laboratory Animals and Environmental Facilities' and the relevant laboratory animal experiment regulations of Chengdu Medical College for the care and use of animals.

Open Access Statement: This is an Open Access article distributed in accordance with the Creative Commons Attribution-NonCommercial-NoDerivs 4.0 International License (CC BY-NC-ND 4.0), which permits the noncommercial replication and distribution of the article with the strict proviso that no changes or edits are made and the original work is properly cited (including links to both the formal publication through the relevant DOI and the license). 
See: https://creativecommons.org/licenses/by-nc-nd/4.0/.

\section{References}

1. Brugnara L, Novials A, Ortega R, et al. Clinical characteristics, complications and management of patients with type 2 diabetes with and without diabetic kidney disease (DKD): A comparison of data from a clinical database. Endocrinol Diabetes Nutr 2018;65:30-8

2. Saxena R, Madhu SV, Shukla R, et al. Postprandial hypertriglyceridemia and oxidant stress in patients of type 2 diabetes mellitus with macrovascular complications. Clin Chim Acta 2005;359:101-8. Erratum in: Clin Chim Acta 2006;368:203.

3. Johnson EL. Glycemic variability in type 2 diabetes mellitus: oxidant stress and macrovascular complications. Adv Exp Med Biol 2012;771:139.

4. Ueda S, Yamagishi S, Kaida Y, et al. Asymmetric dimethylarginine may be a missing link between cardiovascular disease and chronic kidney disease. Nephrology (Carlton) 2007;12:582-90.

5. Zoccali C. The endothelium as a target in renal diseases. J Nephrol. 2007;20 Suppl 12:S39-44.

6. Böger RH. The pharmacodynamics of L-arginine. Altern Ther Health Med. 2014 May-Jun;20(3):48-54.

7. Jia SJ, Jiang DJ, Hu CP, et al. Lysophosphatidylcholineinduced elevation of asymmetric dimethylarginine level by the NADPH oxidase pathway in endothelial cells. Vascul Pharmacol 2006;44:143-8.

8. Pope AJ, Druhan L, Guzman JE, et al. Role of DDAH1 in lipid peroxidation product-mediated inhibition of endothelial NO generation. Am J Physiol Cell Physiol 2007;293:C1679-86.

9. Böger RH, Bode-Boger SM, Szuba A, et al. Asymmetric dimethylarginine (ADMA): a novel risk factor for endothelial dysfunction: its role in hypercholesterolemia. Circulation 1998;98:1842-7.

10. Miyazaki H, Matsuoka H, Cooke JP, et al. Endogenous nitric oxide synthase inhibitor: a novel marker of atherosclerosis. Circulation 1999;99:1141-6.

11. Tarnow L, Hovind P, Teerlink T, et al. Elevated plasma asymmetric dimethylarginine as a marker of cardiovascular morbidity in early diabetic nephropathy in type 1 diabetes. Diabetes Care 2004;27:765-9.

12. Zoccali C, Bode-Boger S, Mallamaci F, et al. Plasma concentration of asymmetrical dimethylarginine and mortality in patients with terminal-stage renal disease: a prospective study. Lancet 2001;358:2113-7.
13. Tang J, Kao PN, Herschman HR. Protein-arginine methyltransferase I, the predominant protein-arginine methyltransferase in cells, interacts with and is regulated by interleukin enhancer-binding factor 3. J Biol Chem 2000;275:19866-76.

14. Ogawa T, Kimoto M, Sasaoka K. Occurrence of a new enzyme catalyzing the direct conversion of NG,NGdimethyl-L-arginine to L-citrulline in rats. Biochem Biophys Res Commun 1987;148:671-7.

15. Pope AJ, Karuppiah K, Cardounel AJ. Role of the PRMTDDAH-ADMA axis in the regulation of endothelial nitric oxide production. Pharmacol Res 2009;60:461-5.

16. Münzel T, Daiber A, Ullrich V, et al. Vascular consequences of endothelial nitric oxide synthase uncoupling for the activity and expression of the soluble guanylyl cyclase and the cGMP-dependent protein kinase. Arterioscler Thromb Vasc Biol 2005;25:1551-7.

17. Vallance P, Leiper J. Asymmetric dimethylarginine and kidney disease--marker or mediator? J Am Soc Nephrol 2005;16:2254-6.

18. Jiang JL, Li Ns NS, et al. Probucol preserves endothelial function by reduction of the endogenous nitric oxide synthase inhibitor level. Br J Pharmacol 2002;135:1175-82.

19. Jiang JL, Zhang XH, Li NS, et al. Probucol decreases asymmetrical dimethylarginine level by alternation of protein arginine methyltransferase I and dimethylarginine dimethylaminohydrolase activity. Cardiovasc Drugs Ther 2006;20:281-94.

20. Yasuda G, Yatsu K, Ando D, et al. Effects of atorvastatin versus probucol on low-density lipoprotein subtype distribution and renal function in hyperlipidemic patients with nondiabetic nephropathy. Ren Fail 2010;32:680-6.

21. Liu JH, Liu DF, Wang NN, et al. Possible role for the thioredoxin system in the protective effects of probucol in the pancreatic islets of diabetic rats. Clin Exp Pharmacol Physiol 2011;38:528-33.

22. Gary JD, Clarke S. RNA and protein interactions modulated by protein arginine methylation. Prog Nucleic Acid Res Mol Biol 1998;61:65-131.

23. Omer S, Shan J, Varma DR, et al. Augmentation of diabetes-associated renal hyperfiltration and nitric oxide production by pregnancy in rats. J Endocrinol 1999;161:15-23.

24. Hanefeld M, Appelt D, Engelmann K, et al. Serum and plasma levels of vascular endothelial growth factors in relation to quality of glucose control, biomarkers of inflammation, and diabetic nephropathy. Horm Metab Res 2016;48:529-534. 
25. Tykhomyrov AA, Shram SI, Grinenko TV. Role of angiostatins in diabetic complications. Biomed Khim 2015;61:41-56.

26. Lindblom R, Higgins G, Coughlan M, et al. Targeting mitochondria and reactive oxygen species-driven pathogenesis in diabetic nephropathy. Rev Diabet Stud 2015;12:134-56.

27. Veelken R, Hilgers KF, Hartner A, et al. Nitric oxide synthase isoforms and glomerular hyperfiltration in early diabetic nephropathy. J Am Soc Nephrol 2000;11:71-9.

28. Komers R, Allen TJ, Cooper ME. Role of endotheliumderived nitric oxide in the pathogenesis of the renal hemodynamic changes of experimental diabetes. Diabetes 1994;43:1190-7.

29. Schmidt RJ, Yokota S, Tracy TS, et al. Nitric oxide production is low in terminal-stage renal disease patients on peritoneal dialysis. Am J Physiol 1999;276:F794-7.

30. Komers R, Anderson S. Paradoxes of nitric oxide in the diabetic kidney. Am J Physiol Renal Physiol 2003;284:F1121-37.

31. Nazir N, Siddiqui K, Al-Qasim S, et al. Meta-analysis of diabetic nephropathy associated genetic variants in inflammation and angiogenesis involved in different biochemical pathways. BMC Med Genet 2014;15:103.

32. An ZM, Dong XG, Guo Y, Zhou JL, Qin T. Effects and clinical significance of pentoxifylline on the oxidant stress of rats with diabetic nephropathy. J Huazhong Univ Sci Technolog Med Sci 2015;35:356-61.

33. Ahmad A, Manjrekar P, Yadav C, Agarwal A, Srikantiah RM, Hegde A. Evaluation of ischemia-modified albumin, malondialdehyde, and advanced oxidative protein products as markers of vascular injury in diabetic nephropathy. Biomark Insights 2016;11:63-8.

34. Böger RH, Vallance P, Cooke JP. Asymmetric dimethylarginine (ADMA): a key regulator of nitric oxide synthase. Atheroscler Suppl 2003;4:1-3.

Cite this article as: Mei X, Zeng J, Liu DF, Zhao Y, Yang HL, Li Y, Qiu P, Tang MW. Abnormalities of the PRMT1-ADMADDAH1 metabolism axis and probucol treatment in diabetic patients and diabetic rats. Ann Palliat Med 2021;10(3):33433353. doi: 10.21037/apm-21-417
35. Leiper J, Vallance P. Biological significance of endogenous methylarginines that inhibit nitric oxide synthases. Cardiovasc Res 1999;43:542-8.

36. Tran CT, Leiper JM, Vallance P. The DDAH/ADMA/ NOS pathway. Atheroscler Suppl 2003;4:33-40.

37. Davì G, Ciabattoni G, Consoli A, et al. In vivo formation of 8-iso-prostaglandin f2alpha and platelet activation in diabetes mellitus: effects of improved metabolic control and vitamin E supplementation. Circulation 1999;99:224-9.

38. Lin KY, Ito A, Asagami T, et al. Impaired nitric oxide synthase pathway in diabetes mellitus: role of asymmetric dimethylarginine and dimethylarginine dimethylaminohydrolase. Circulation 2002;106:987-92.

39. Onozato ML, Tojo A, Leiper J, et al. Expression of NG, NG-dimethylarginine dimethylaminohydrolase and protein arginine $\mathrm{N}$-methyltransferase isoforms in diabetic rat kidney: effects of angiotensin II receptor blockers. Diabetes 2008;57:172-80.

40. Parthasarathy S, Young SG, Witztum JL, et al. Probucol inhibits oxidative modification of low density lipoprotein. J Clin Invest 1986;77:641-4.

41. Nishimura M, Sasaki T, Ohishi A, et al. Angiotensinconverting enzyme inhibitors and probucol suppress the time-dependent increase in urinary Type IV collagen excretion of Type II diabetes mellitus patients with early diabetic nephropathy. Clin Nephrol 2001;56:96-103.

42. Endo K, Miyashita Y, Sasaki H, et al. Probucol delays progression of diabetic nephropathy. Diabetes Res Clin Pract 2006;71:156-63.

43. Chakraborty A, Chowdhury S, Bhattacharyya M. Effect of metformin on oxidant stress, nitrosative stress and inflammatory biomarkers in type 2 diabetes patients. Diabetes Res Clin Pract 2011;93:56-62.

(English Language Editor: J. Jones) 